\title{
Cationic Polybutyl Cyanoacrylate Nanoparticles for DNA Delivery
}

\author{
Jinghua Duan, ${ }^{1}$ Yangde Zhang, ${ }^{1}$ Wei Chen, ${ }^{1}$ Chengrong Shen, ${ }^{1}$ Mingmei Liao, ${ }^{1}$ Yifeng Pan, ${ }^{1}$ \\ Jiwei Wang, ${ }^{1}$ Xingming Deng, ${ }^{2,3}$ and Jinfeng Zhao ${ }^{1}$ \\ ${ }^{1}$ Key Laboratory of Nanobiological Technology, Ministry of Health National Hepatobiliary and Enteric Surgery Research Center, \\ Central South University, Changsha, Hunan 410008, China \\ ${ }^{2}$ Shands Cancer Center, University of Florida, Gainesville, FL 32610-0232, USA \\ ${ }^{3}$ Department of Medicine, University of Florida, Gainesville, FL 32610-0232, USA
}

Correspondence should be addressed to Jinfeng Zhao, zhaojinfeng@hotmail.com

Received 4 July 2008; Revised 3 December 2008; Accepted 25 December 2008

Recommended by Hicham Fenniri

\begin{abstract}
To enhance the intracellular delivery potential of plasmid DNA using nonviral vectors, we used polybutyl cyanoacrylate (PBCA) and chitosan to prepare PBCA nanoparticles (NPs) by emulsion polymerization and prepared NP/DNA complexes through the complex coacervation of nanoparticles with the DNA. The object of our work is to evaluate the characterization and transfection efficiency of PBCA-NPs. The NPs have a zeta potential of $25.53 \mathrm{mV}$ at $\mathrm{pH} 7.4$ and size about $200 \mathrm{~nm}$. Electrophoretic analysis suggested that the NPs with positive charges could protect the DNA from nuclease degradation and cell viability assay showed that the NPs exhibit a low cytotoxicity to human hepatocellular carcinoma (HepG2) cells. Qualitative and quantitative analysis of transfection in HepG2 cells by the nanoparticles carrying plasmid DNA encoding for enhanced green fluorescent protein (EGFPN1) was done by digital fluorescence imaging microscopy system and fluorescence-activated cell sorting (FACS). Qualitative results showed highly efficient expression of GFP that remained stable for up to 96 hours. Quantitative results from FACS showed that PBCA-NPs were significantly more effective in transfecting HepG2 cells after 72 hours postincubation. The results of this study suggested that PBCA-NPs have favorable properties for nonviral delivery.
\end{abstract}

Copyright ( $) 2009$ Jinghua Duan et al. This is an open access article distributed under the Creative Commons Attribution License, which permits unrestricted use, distribution, and reproduction in any medium, provided the original work is properly cited.

\section{Introduction}

Hepatocellular carcinoma (HCC) is a liver cancer prevalent in Asia, especially in the Mainland China $[1,2]$. As an established human hepatocarcinoma cell line with epithelial morphology, HepG2 cells are used routinely for a variety of biochemical and cell biological studies [3-5].

The barrier to gene delivery, nuclease degradation in the lysosomal compartment, has been the focus of many investigators. Important research has been moving toward the development of polycation-based gene-delivery systems (such as polylysine conjugates) designed to minimize nuclease degradation through the design of vectors with the capacity to escape the endosomal-lysosomal pathway [6-8]. Behr and others introduced the concept of the "proton sponge" and hypothesized that polymers with buffering capacities between 7.2 and 5.0, such as polyethylenimine (PEI) and imidazole-containing polymers, could buffer the endosome and potentially induce its rupture. Protein-expression levels mediated by the polycationic proton-sponge polymer, PEI, were at least 10-fold greater than polylysine alone [9-12]. However, protein expression after delivery of plasmid DNA to the cell nucleus depends on the processes of transcription and translation. Cytotoxic gene-delivery systems may compromise these processes and potentially limit protein expression. These situations are perhaps the most prevalent in the nonviral polycationic gene-delivery class in which the polycationic nature of the delivery system can lead to cytotoxicity. To drive gene therapy ultimately into the clinic, improved delivery systems, or vectors, must deliver DNA to the cell in a transcriptionally active form and must fulfill all regulatory agency mandates to be considered safe for use in humans [13-16].

PBCA particles are extensively investigated for gene and drug delivery, but now most investigated stabilizers for PBCA lead to negatively charged particles [17]. In an 
attempt to provide a positive charge to a colloidal system, chitosan has been used in the preparation and stabilization of polyester nanocapsules [18, 19], nanoparticles [20], submicron-sized emulsions [18], microcapsules [21], and liposome [22]. Chitosan is a cationic high-molecular-weight heteropolysaccharide composed mainly of b-(1,4)-2-deoxy2-amino-D-glucopyranose units and partially of b- $(1,4)-2$ deoxy-2-acetamido-D-glucopyranose. Because of favorable biological properties such as biodegradability, biocompatibility, and nontoxicity, chitosan has attracted great attention in pharmaceutical and biomedical fields [23-28]. Chitosan also increases the transcellular and paracellular transport across epithelium [29].

The aim of the study was to develop positively charged polybutyl cyanoacrylate (PBCA)-NPs in the presence of chitosan for the potential use as a targeting gene delivery system. Physicochemical characteristics of the prepared nanoparticles were examined by dynamic light scattering, transmission electron microscopy, and Fourier transform infrared (FT-IR) spectroscopy. The transfection efficiency of the prepared NPs into HepG2 cells was examined in vitro using digital fluorescence imaging microscopy system and fluorescence-activated cell sorting (FACS).

\section{Materials and Methods}

2.1. Materials. Chitosan (degree of deacetylation $=90 \%$ ) was purchased from (Shanghai Bio Life Science \& Technology Co., Ltd. Shanghai, China). Butyl cyanoacrylate (BCA) monomer was synthesized by (Guangzhou Baiyun Medical Adhensive Co., Ltd. Guangzhou, China). HepG2 cell lines were provided by ourselves. All other chemicals used were of analytical reagent grade and without further purification. Ultrapure water was used for the preparation of all solutions.

2.2. PBCA Nanoparticles. PBCA-NPs were prepared by emulsion polymerization as described in detail elsewhere [30-35]. Briefly, the desired amount $(100 \mu \mathrm{L})$ of BCA monomer was dropped into an acidic solution of chitosan adjusted with $1 \mathrm{~mol} / \mathrm{L}$ hydrochloric acid at room temperature, $\mathrm{pH}$ 1.5, under constant magnetic stirring, stirring was maintained for at least 6 hours until the polymerization was complete. The colloidal suspension obtained was brought to $\mathrm{pH}$ value of 5.5 by adding $0.5 \mathrm{~mol} / \mathrm{L} \mathrm{NaOH}$.

2.3. Fourier Transform Infrared (FT-IR) Spectrometer. FT-IR spectra were recorded on a spectrophotometer TENSOR 27 (Bruker, Billerica, Mass, USA). Test samples used for the FTIR analysis first were dried and ground into a powder. The powder then was mixed with $\mathrm{KBr}$ and pressed into a disk. The samples were scanned from $400-4000 \mathrm{~cm}^{-1}$.

2.4. Particle Size and Zeta Potential. The size of PBCANPs was assessed using a dynamic light scattering spectrophotometer Zetasizer $1000 \mathrm{HS}_{\mathrm{A}}$ (Malvern Instruments Ltd., Worcestershire, UK). The colloidal suspension of the NPs was diluted with deionized distilled water, and the particle size analysis was carried out at a scattering angle of $90^{\circ} \mathrm{C}$ and a temperature of $25^{\circ} \mathrm{C}$.
The zeta potential was measured on Zetasizer Nano system (Malvern Instruments Ltd., Worcestershire, UK). The measurement was done in $10 \mathrm{mmol} / \mathrm{L} \mathrm{NaCl}$ using disposable zeta cells using the general purpose protocol at $25^{\circ} \mathrm{C}$. The instrument was calibrated routinely with a $-50 \mathrm{mV}$ latex standard. The mean zeta potential was determined using phase analysis light scattering technique.

\subsection{Transmission Electron Microscopy (TEM) Observation.} Particle morphology of PBCA-NPs was observed by transmission electron microscopy (TEM) using a Hitachi H-600 at $50 \mathrm{kV} .1 \mathrm{~mL}$ dispersion was diluted with $1 \mathrm{~mL}$ demineralized water and a drop of it was placed onto a collodion support on copper grids (200 mesh). About 2 minutes of deposition, the grid was tapped with a filter paper to remove surface water and negatively stained by using a sodium phosphotungstate for 5 seconds. The grid was allowed to dry further for 10 minutes and was then examined with the electron microscope.

2.6. Preparation of NP/DNA Complexes. EGFP-N1 driven by immediate early promoter of cytomegalovirus (CMV) was purchased from (Clontech Laboratories, Palo Alto, Calif, USA). The plasmids were propagated in Escherichia coli, extracted by the alkali lysis technique [36], and purified by an EZ-10 Spin Column Plasmid Mini-Preps kit (Bio Basic Inc, Calif, USA) according to the manufacturer's instruction. DNA purity was determined by measuring the optical density (OD), and DNA with OD260/OD280 $\geq 1.8$ was used.

NP/DNA complexes were prepared through the complex coacervation of the cationic polymer (PBCA-NPs) with the EGFP-N1 plasmid. Microliters of pDNA $(100 \mu \mathrm{g} / \mathrm{mL})$ were added into PBCA-NPs solution, which had been filtrated through a $0.45 \mu \mathrm{m}$ filter and mixed with them in $10 \mathrm{mmol} / \mathrm{L}$ phosphate buffer ( $\mathrm{pH}$ 7.4). The mixed liquor was standing for 30 minutes at room temperature and the complexes were used for further study. Complexes formation was confirmed by electrophoresis on a $1.0 \%$ agarose gel with TBE buffer ( $89 \mathrm{mmol} / \mathrm{L}$ Tris, $89 \mathrm{mmol} / \mathrm{L}$ boric acid, and $2 \mathrm{mmol} / \mathrm{L}$ EDTA $\mathrm{pH} 8.0$ ) at $75 \mathrm{~V}$ for 90 minutes. DNA was visualized by staining gels with ethidium bromide $(0.5 \mu \mathrm{g} / \mu \mathrm{L})$. Images were acquired using an UV transilluminator (VILBER LOURMAT, France).

2.7. Stability of NP/DNA Complexes. Nanoparticles suspension or naked DNA was incubated with $4 \mu \mathrm{L}$ DNase I $(1 \mathrm{U} / \mu \mathrm{L})$ in DNase I Buffer, which consisted of $100 \mathrm{mmol} / \mathrm{L}$ Tris- $\mathrm{HCl}, 25 \mathrm{mmol} / \mathrm{L} \mathrm{MgCl}_{2}$, and $1 \mathrm{mmol} / \mathrm{L} \mathrm{CaCl}_{2}$ at $37^{\circ} \mathrm{C}$ for 1hours. Samples of naked DNA, undigested and digested complexes were loaded onto a $1.0 \%$ agarose gel in Trisborate EDTA buffer at $\mathrm{pH}$ 8.0. The samples were run on the gel at $75 \mathrm{~V}$ for 90 minutes; the gel was stained with ethidium bromide $(0.5 \mu \mathrm{g} / \mu \mathrm{L})$.

2.8. Cell Uptake Study. HepG2 cells were incubated in Dulbecco's modification of eagle's medium (DMEM, Beijing Solarbio Science \& Technology Co., Ltd, Beijing, China) at 


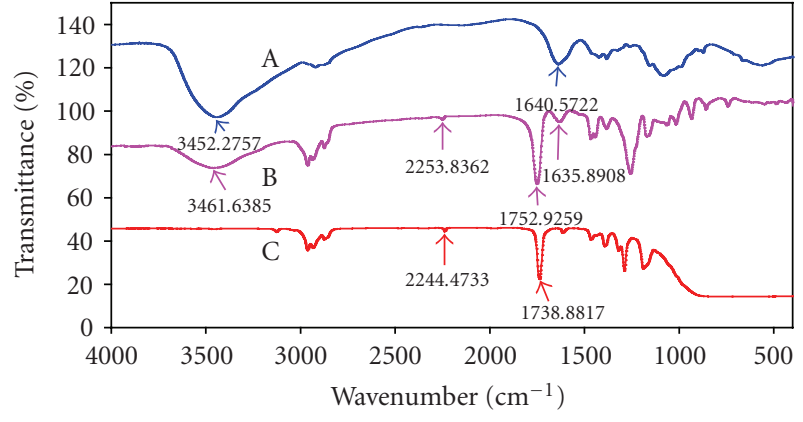

FIGURE 1: (A) Fourier transform IR spectra of chitosan; (B) chitosan-coated PBCA-NPs; (C) PBCA-NPs.

$37^{\circ} \mathrm{C}, 5 \% \mathrm{CO}_{2}$ with $10 \%$ fetal bovine serum (FBS) and $100 \mathrm{U} / \mathrm{mL}$ penicillin-streptomycin.

A confluent layer of approximately 8000 HepG2 cells per well was incubated with 20 microliters fluorescent NP suspension, the final concentration of NPs in the serumfree medium was $210 \mu \mathrm{g} / \mathrm{mL}$, in the 6-well black plates at $37^{\circ} \mathrm{C}$. After 6 hours of incubation, the cells were washed three times with cold PBS (pH 7.4) to eliminate excess particles which were not entrapped by the cells. The uptake of NPs by the HepG2 cells was examined with fluorescence microscopy Leica DM LB2 (Leica Microsystems Wetzlar $\mathrm{GmbH}$, Germany). In the control experiment, there were no fluorescent NPs in the medium.

To preparing for flow cytometry, after digested with the lyse solution containing $0.25 \%$ trypsin, the cocultivated cells were harvested and rinsed with cooled D-Hank's solution and centrifuged (1000 rpm, 5 minutes) to discard cell fragments. The cells were further washed three times with PBS and centrifuged (1000 rpm, 5 minutes) to remove the uncombined nanoparticles. The obtained cells were diluted to single-cell suspension stabilized with $1 \%$ formaldehyde at $4^{\circ} \mathrm{C}$. Processed single-cell suspensions were analyzed on an FACS Calibur flow cytometer (BD, Franklin Lakes, NJ, USA) using a $488 \mathrm{~nm}$ argon laser and FL1 bandpass emission $(530 \pm 20 \mathrm{~nm})$ for the green fluorescence. HepG2 cells were gated by sideward scatter versus forward scatter (SSC/FSC) plots. Fluorescence measurements were done in the FL1 channel.

2.9. Cytotoxicity Evaluation by MTT Assay. Cytotoxicity of the NPs was determined by (3-(4,5-dimethylthiazol-2-yl)2,5-diphenyltetrazolium bromide) MTT assay in HepG2 cells. This assay is based on the ability of living cells to reduce a water-soluble yellow dye, MTT, to a purple colored water-insoluble formazan product by mitochondrial enzyme succinate dehydrogenase. The cells were maintained in DMEM supplemented with $10 \% \mathrm{FBS}$ in $5 \% \mathrm{CO}_{2}$ incubator at $37^{\circ} \mathrm{C}$. Eight thousand cells were seeded per well in 96-well microtiter plates followed by incubation for 24 hours. The growth medium was replaced with a fresh one containing $0.1-8.0 \mu \mathrm{g} / \mu \mathrm{L}$ NPs. After 24 -hour incubation, $20 \mu \mathrm{L}$ of MTT solution $(5 \mathrm{mg} / \mathrm{mL}$ in PBS, $\mathrm{pH} 7.4)$ was added to cells followed by further incubation for 4 hours. Thereafter, the media was removed and cells were rinsed with PBS. The formazan crystals formed were dissolved using dimethyl sulfoxide (DMSO) $(150 \mu \mathrm{L} /$ well) and absorbance was read at $570 \mathrm{~nm}$ on a multiskan spectrum (Electro Thermo, Milford, Mass, USA). Cell viability was determined as a percentage of the negative control (untreated cells).

2.10. In Vitro Transfection. For the qualitative analysis of transfection, HepG2 cells were grown in 6-well culture plates containing a Corning circular glass cover-slip with seeded $1 \times 10^{5}$ cells seeded per well and incubated until the cover rate reached $60-80 \%$. The NP/DNA complexes were dispersed in serum-free medium and untreated cells were used as a negative control. After filtration, the NP/DNA complexes were added at a concentration equivalent to $2 \mu \mathrm{g}$ of EGFPN1 plasmid DNA per well, and incubated with the cells at $37^{\circ} \mathrm{C}$ and $5 \% \mathrm{CO}_{2}$ atmosphere for 6 hours. The culture was removed from each well and replaced with regular growth medium including 10\% FBS. The cover slips were washed three times with PBS at 96 hours posttransfection and mounted on to microscopic slides containing a drop of antifade mounting medium (Beyotime Institute of Biotechnology, Shanghai, China). The expression of GFP in the cells was observed by a fluorescence microscope.

For the quantitative analysis of transfection, HepG2 cells were grown to semiconfluence in a 6-well cell culture plate and transfected with EGFP-N1 plasmid DNA encapsulated PBCA-NPs and compared with cells treated with serumfree media alone. The NP/DNA complexes were dispersed in serum-free media and added to each of the six wells at a concentration of $2 \mu \mathrm{g}$ of plasmid DNA per well. The cells are allowed to incubate for a period of 6 hours at $37^{\circ} \mathrm{C}$ in a $5 \%$ $\mathrm{CO}_{2}$ incubator and then replaced by fresh growth medium. The adherent cells are trypsinized at time intervals of 24 , 48,72 , and 96 hours postincubation, centrifuged, and fixed with $100 \mu \mathrm{L}$ of $4 \%$ formalin buffer solution. The fluorescence of the GFP produced in the transfected cell was detected by a flow cytometer equipped with an argon 488 laser. The FL1 channel was used to detect the cells expressing GFP fluorescence.

\section{Results and Discussion}

3.1. Preparation and Characterization of PBCA-NPs. We synthesized the nanoparticles by dropping monomer into an acidic solution of chitosan. We obtained uniform particles by adding BCA monomer, $\mathrm{pH} 1.5$, at room temperature, to $0.5 \%(\mathrm{w} / \mathrm{v})$ chitosan during high-speed vortexing.

FT-IR analysis was performed to confirm the chitosangraft-PBCA. Figure 1 shows a comparison between the FTIR spectra of chitosan(A), chitosan-coated PBCA(B), and PBCA(C). After chitosan-stabilized NPs had been extracted, the residue still possessed a $-\mathrm{CN}$ stretch $\left(2253.84 \mathrm{~cm}^{-1}\right)$ and a carbonyl stretch $\left(1752.93 \mathrm{~cm}^{-1}\right)$ corresponding to those of PBCA and a hydrogen-bonded $\mathrm{OH}$ stretch $\left(3461.64 \mathrm{~cm}^{-1}\right)$ corresponding to that of chitosan. The amide band at $1640.57 \mathrm{~cm}^{-1}$ that was observed in chitosan shifts to $1635.89 \mathrm{~cm}^{-1}$. These observations suggest that chitosan, especially the $\mathrm{NH}_{2}$ group, may initiate the BCA monomer 


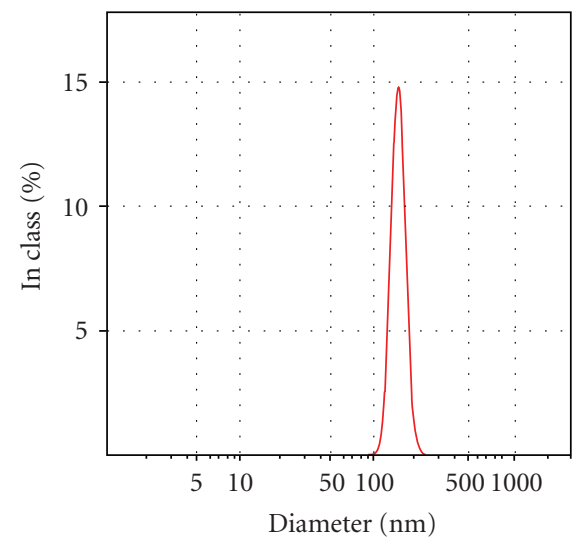

(a)

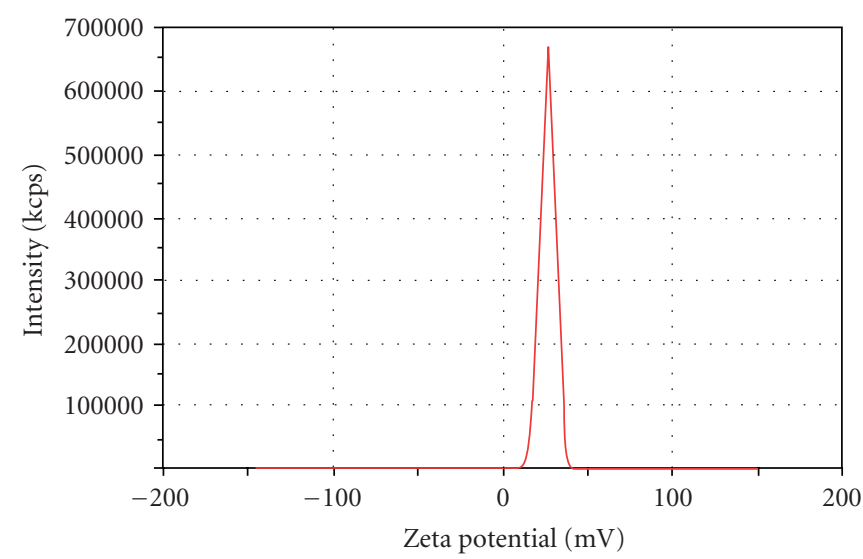

(b)

Figure 2: (a) Size distribution and (b) zeta potential of the prepared chitosan-coated PBCA-NPs.

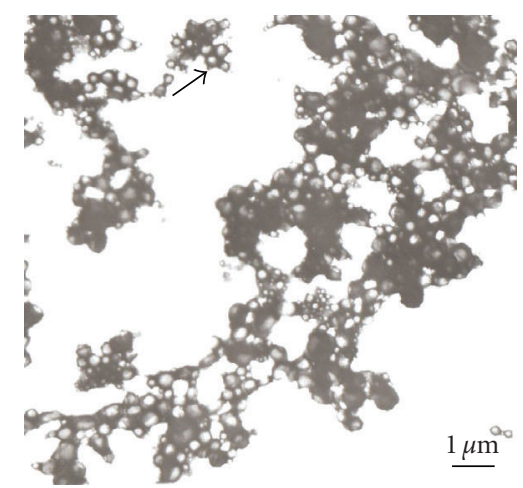

Figure 3: Transmission electron micrograph of the prepared chitosan-coated PBCA nanoparticles.

in the acidic polymerization medium, leading to chitosan chemically coupled to PBCA to form chitosan-stabilized NPs.

The size distribution and zeta potential of the NPs in $\mathrm{NaCl}$ solution were investigated by dynamic light scattering. Dynamic size distribution and zeta potential may play important roles in determining the fate of NPs after administration [37]. Figure 2(a) shows a unimodal particle size distribution (number average) between 100 and $200 \mathrm{~nm}$. It was reported that large particles hardly reach the cells [38], while smaller particles tended to accumulate in the tumor sites due to the enhanced permeability and retention (EPR) effect and a greater internalization was also observed [6]. Additionally, gene carriers with a diameter larger than $200 \mathrm{~nm}$ are readily scavenged nonspecifically by monocytes and the reticuloendothelial system [39].

The results of Figure 2(b) indicated that PBCA-NPs carry positive charge with a zeta potential of about $25 \mathrm{mV}$. PBCA-NPs have a very negative zeta potential because of the adsorption of anions from the aqueous polymerization medium, but chitosan is a polycationic biopolymer, positive charge PBCA-NPs may have been produced by coating them with chitosan $[40,41]$.

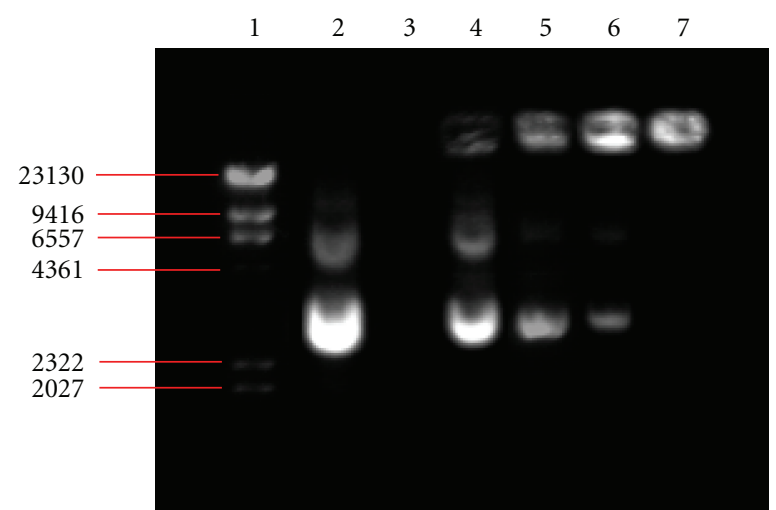

Figure 4: Agarose gel electrophoresis of NP/DNA complexes. Lane 1: DNA molecular weight marker; lane 2: naked plasmid DNA; lane 3: chitosan-coated PBCA-NPs; lanes 4-7 correspond to DNA with progressively increasing proportions of NPs at the charge ratio of 5:1, 10:1, 15:1, and 30:1 (w/w), respectively.

In theory, more pronounced zeta potential values, being positive or negative, tend to stabilize particle suspension due to the electrostatic repulsion forces between particles with the same electric charge prevents the aggregation of the spheres [42]. Consequently, the presence of the positively charged groups on the particles could lead to electrical charge interactions between the negatively charged surface cells and the particles [43].

TEM images shown in Figure 3 reveal the surface morphology and spherical shape of the prepared particles. The actual diameter of the nanoparticles observed by TEM was approximately $200 \mathrm{~nm}$ and was found to be similar to the values obtained by measurements based on light scattering. The plasmid is protected from DNase degradation in this formulation [44].

3.2. Complex Formation of PBCA-NPs With pEGFP-N1 Plasmid DNA. pDNA complex with previously prepared nanoparticles was achieved by the formation of ion-pairs between the positively charged amino groups located on the 


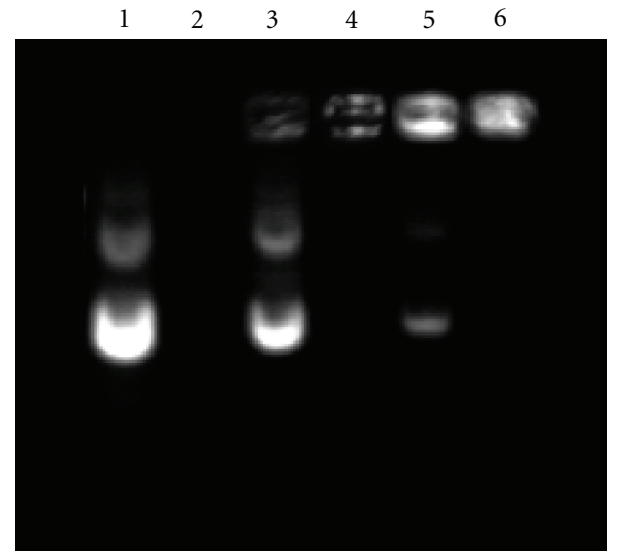

FIGURE 5: Electrophoretic mobility analysis NP/DNA complexes following DNase I digestion. Lane 1: EGFP-N1 plasmid DNA; lane 2: lane 1 + digestion; lane 3: NP/DNA complex at the charge of 5:1; lane 4: lane 3 + digestion; lane 5: NP/DNA complex at the charge of 15:1; lane 6: lane $5+$ digestion.

particle surface and the negatively charged phosphodiester backbone of the plasmid DNA [45]. The electrophoretic mobility of DNA, complex with PBCA-NPs, decreases gradually on the agarose gel with increasing charge ratio (Figure 4). However, in the control experiment, there was no DNA in agarose gel. This method also allowed showing the dependency of this interaction on $\mathrm{pH}$, reflecting the deprotonation of the modified silica particles at alkaline $\mathrm{pH}$ (data not shown). The particle-DNA binding was also inhibited by the presence of high salt concentrations (data not shown). This suggests that this interaction is based on electrostatic forces, resulting in interpolyelectrolyte complexes.

3.3. Enzyme Protection. Behr introduced the concept of the "proton sponge" and hypothesized that polymers with buffering capacities between 7.2 and 5.0 could buffer the endosome and potentially induce its rupture [46]. As the chitosan molecule is a weak base with a $\mathrm{pKa}$ value of the D-glucosamine residue about 6.2-7.0 [47], we hypothesize NP/DNA complexes formation can resist enzymatic degradation. The results were analyzed by using agarose gel electrophoresis. Figure 5 shows that free-plasmid DNA was degraded completely into small fragments and could not be visualized in the agarose gel, however, NP/DNA complexes digested by DNase I were still visualized around the sample pore.

3.4. Cytotoxicity Evaluation of NP/DNA Complexes. In vitro toxicity of NP/DNA complexes was evaluated by MTT assay in HepG2 cells using increasing doses of NPs. MTT assay shows that the cytotoxicity of the NPs depended on their concentration ranging from $0.1-8.0 \mu \mathrm{g} / \mu \mathrm{L}$ (Figure 6). The statistic analysis demonstrates that there are significant differences between concentrations (one-way ANOVA, $P<$ .001 ). These data can indicate that the NPs below $2 \mu \mathrm{g} / \mu \mathrm{L}$ had little adverse effect on the HepG2 cells viability, suggesting that the doses of in vitro HepG2 cells uptake study less

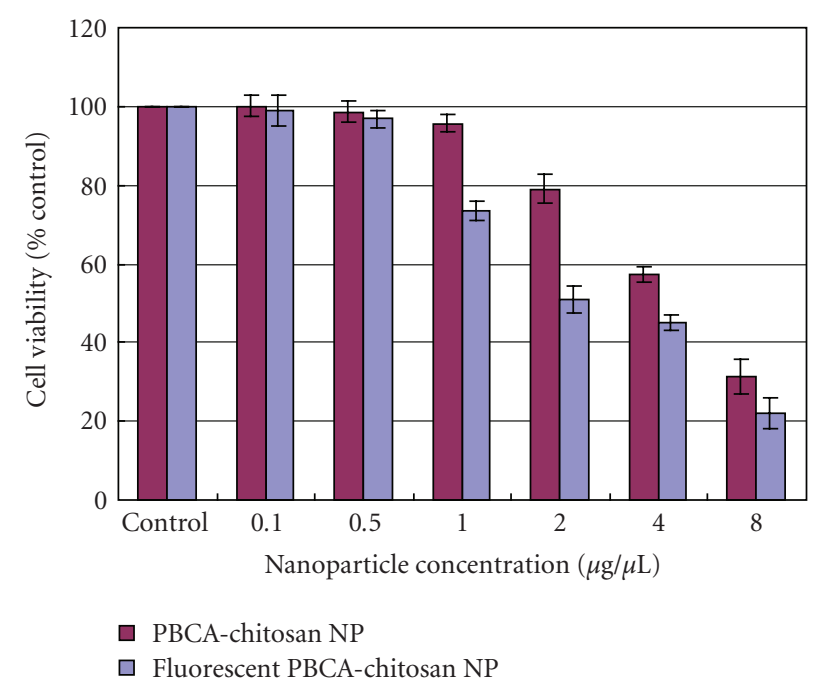

FIgUre 6: Cytotoxicity of cationic chitosan coated PBCA-NPs analyzed by MTT assay, 24 hours posttreatment $(n=8)$. Columns, mean; bars, $\mathrm{SD}, P<.001$ as evaluated by one-way ANOVA using SPSS 17.0 version.

than $0.5 \mu \mathrm{g} / \mu \mathrm{L}$ presented no toxicity. This is important because most of the cationic polymers and lipids, which are commonly used for gene transfection, have toxic effects on cells at a higher concentration due to electrostatic interaction with negatively charged cellular membrane $[48,49]$. Thus, the PBCA-NPs is a promising carrier for gene delivery with low cytotoxicity. However, its long-term in vivo toxicity and immunogenicity should be further investigated.

3.5. Uptake of the Functionalized PBCA-NPs. In order to study cellular uptake of NPs in vitro, the use of fluorescently or radioactively labeled NPs is the most common experimental approach found in the literature. Fluorescent labeling, which we used the prepared fluorescent positive PBCA-NPs in this study, was chosen for the present study to avoid exposure of the samples to radioactive materials. Fluorescent labeling makes cellular uptake of NPs readily detectable by fluorescence microscopy. The extent of particle uptake can then be determined by flow cytometry. After incubation of HepG2 cells with the fluorescent PBCA-NPs for 6 hours, the FACS measurements showed significantly higher mean fluorescence intensity of $75.06 \%$ for cells incubated with the positively charged fluorescent $\mathrm{PBCA}-\mathrm{NPs}$ with respect to the control particles (see Figure 7).

Figure 8 shows fluorescent microscopic images of HepG2 cell monolayers after the NPs uptake experiments, which strongly support the previous quantitative measurements of the cellular uptake of the NPs by showing strong fluorescence in the cell. However, no fluorescence can be detected from the image of the control cells.

3.6. In Vitro Gene Transfection and Expression in HepG2 Cells. In order to evaluate the effect of PBCA-NPs on transferring DNA, we investigated the transfection efficiency of complexes containing pDNA in HepG2 cells to find gene 


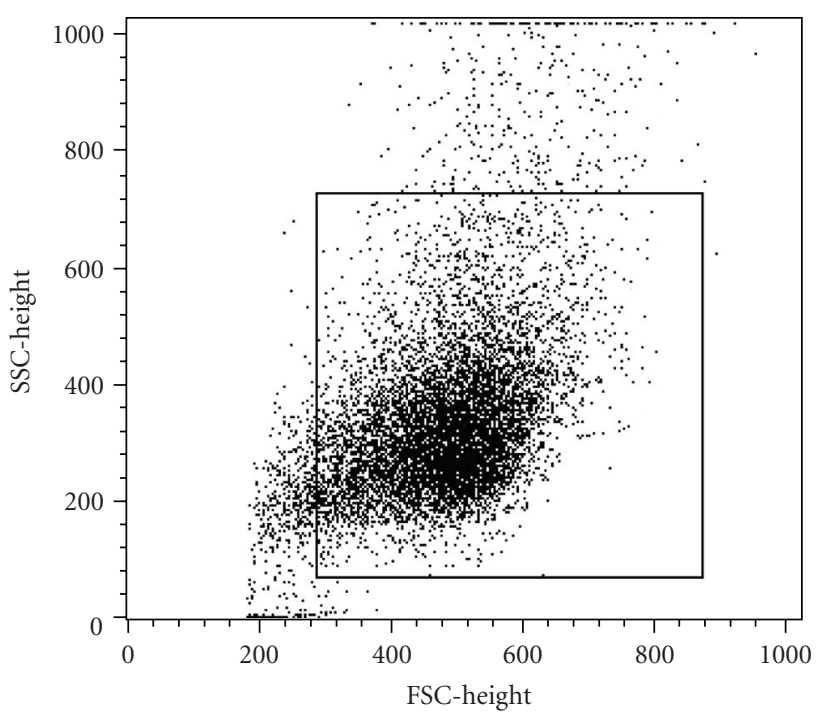

(a)

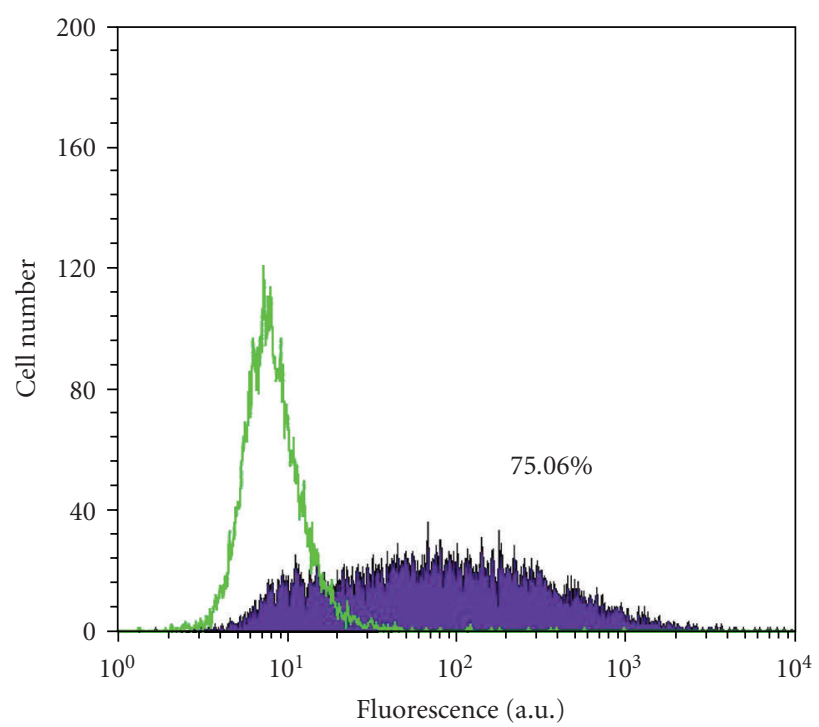

(b)

FIGURE 7: (a) Quantitative analysis intracellular fluorescence of HepG2 cells; (b) endocytosised with fluorescent chitosan-coated PBCA-NPs by flow cytometry.

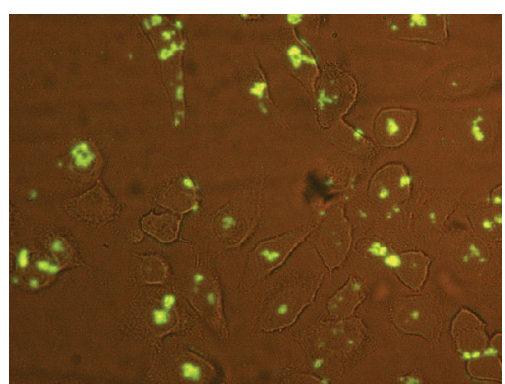

(a)

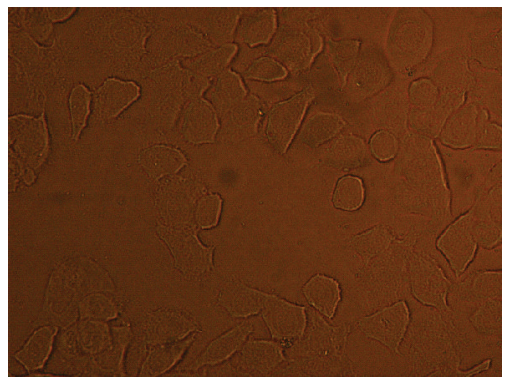

(b)

FIGURE 8: Biocompatibility of functionalized chitosan-coated PBCA-NPs $(\times 200)$. (a) HepG2 cell endocytosised fluorescent chitosan-coated PBCA-NPs; (b) HepG2 cell without fluorescent chitosan-coated PBCA-NPs.

expression level. The concentration of PBCA-NPs used in this experiment was much less than $0.5 \mu \mathrm{g} / \mu \mathrm{L}$, which would not affect the cell viability obviously according to the result mentioned in cell viability assay.
The pictures of fluorescence microscope to detect the green fluorescence sent out by transfected cells indicated relatively higher transfection efficiencies of NP/DNA complexes (Figure 9(a)). To determine the gene transfer capability of NPs in vitro exactly, flow cytometry experiments were conducted to determine the EGFP transfection levels in HepG2 cells. It was found that the transgene expression levels increased with the time, and reached a climax at 72 hours, then decreased. The results of the complexes are fused with cell membrane easily through electrostatical interaction can be explained by the fact that complexes possess the positive potential in neutral conditions.

\section{Conclusions}

From these investigations, it is evident that this method forms uniform cationic PBCA nanospheres which can bind DNA readily by electrostatic interaction. Chitosan cannot only chemically couple to PBCA giving the net positive surface charge, but also produced particles with uniform size and spherical shape, as observed by TEM. By applying emulsion polymerization technique, it is possible to prepare fluorescent dye labeled PBCA-NPs. In the present study, we identify that chitosan-coated PBCA-NPs are positive charge and can be used as nonviral carrier for gene transfection.

Compared with negatively charged NPs, positively charged NP/DNA complexes might prevent destabilization by cation adsorption, give a better controlled release of plasmid, favorably interact with negatively charged tissues and provide site-specific target in vivo. Therefore, positively charged targeting gene delivery vehicles may be considered as very promising gene carriers for various administration routes. 


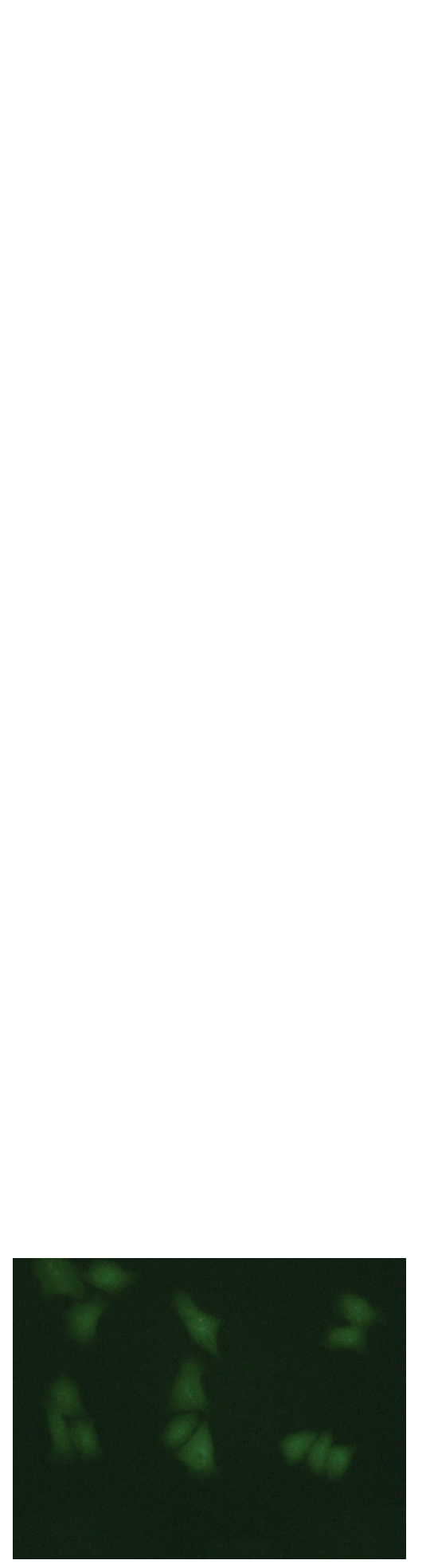

(a)
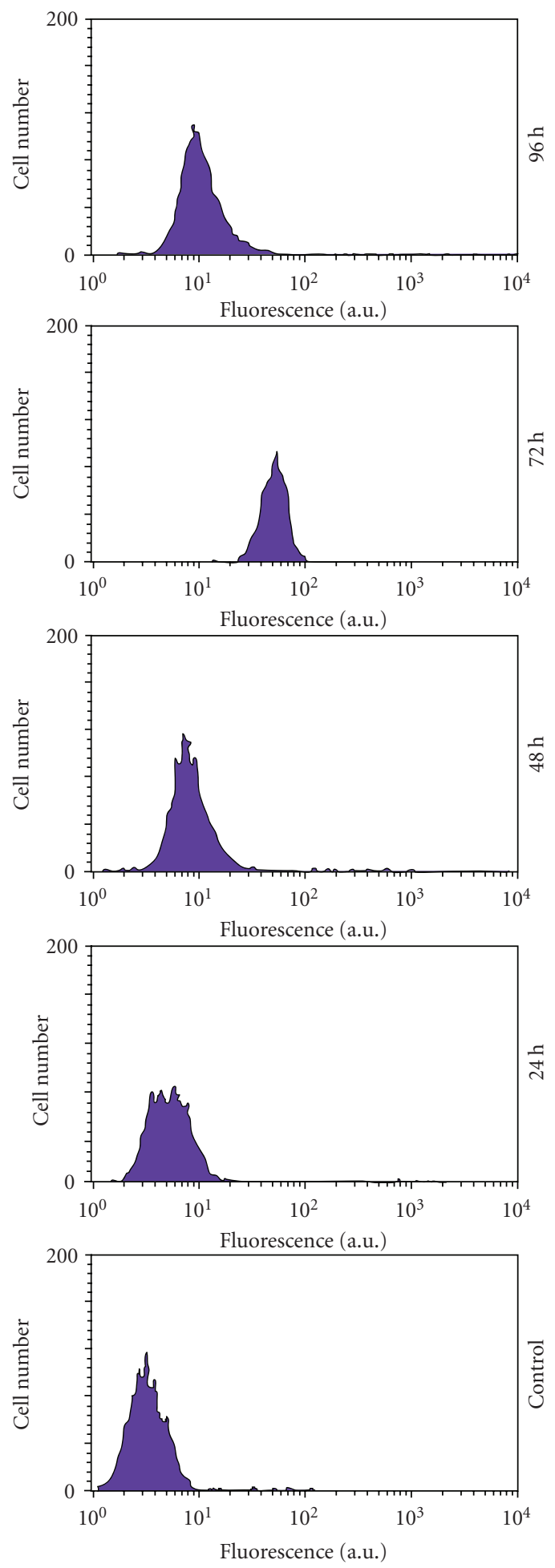

(b)

FIgURE 9: (a) Qualitative evaluation of EGFP-N1 transgene expression in HepG2 cells with chitosan-coated PBCA-NPs, fluorescent image ( $\times 200)$ of the cells was obtained after 96 hours upon incubation. (b) Quantitative evaluation of EGFP-N1 transgene expression in HepG2 cells as a function of time measured by flow cytometric analysis with chitosan-coated PBCA-NPs. HepG2 cells without any treatment were used as control. 


\section{Acknowledgment}

This work was supported by National "Tenth Five-Year Project" 863 Program of China (no. 2002AA216011). The first two authors contributed equally to this work.

\section{References}

[1] Z.-Y. Tang, "Hepatocellular carcinoma-cause, treatment and metastasis," World Journal of Gastroenterology, vol. 7, no. 4, pp. 445-454, 2001.

[2] J. W. Park, "Hepatocellular carcinoma in Korea: introduction and overview," The Korean Journal of Gastroenterology, vol. 45, no. 4, pp. 217-226, 2005.

[3] M. Hirayama, Y. Kohgo, H. Kondo, et al., "Regulation of iron metabolism in Hep G2 cells: a possible role for cytokines in the hepatic deposition of iron," Hepatology, vol. 18, no. 4, pp. 874-880, 1993.

[4] L. Mezzasoma, R. Biondi, C. Benedetti, et al., "In vitro production of leukemia inhibitory factor (LIF) by Hep G2 hepatoblastoma cells," Journal of Biological Regulators and Homeostatic Agents, vol. 7, no. 4, pp. 126-132, 1993.

[5] H. Suzuki, K. Seto, Y. Shinoda, et al., "Paracrine upregulation of VEGF receptor mRNA in endothelial cells by hypoxiaexposed Hep G2 cells," American Journal of Physiology. Gastrointestinal and Liver Physiology, vol. 276, no. 1, pp. G92-G97, 1999.

[6] C. Plank, K. Zatloukal, M. Cotten, K. Mechtler, and E. Wagner, "Gene transfer into hepatocytes using asialoglycoprotein receptor mediated endocytosis of DNA complexed with an artificial tetra-antennary galactose ligand," Bioconjugate Chemistry, vol. 3, no. 6, pp. 533-539, 1992.

[7] C. Plank, B. Oberhauser, K. Mechtler, C. Koch, and E. Wagner, "The influence of endosome-disruptive peptides on gene transfer using synthetic virus-like gene transfer systems," The Journal of Biological Chemistry, vol. 269, no. 17, pp. 1291812924, 1994.

[8] E. Wagner, C. Plank, K. Zatloukal, M. Cotten, and M. L. Birnstiel, "Influenza virus hemagglutinin HA-2 N-terminal fusogenic peptides augment gene transfer by transferrinpolylysine-DNA complexes: toward a synthetic virus-like gene-transfer vehicle," Proceedings of the National Academy of Sciences of the United States of America, vol. 89, no. 17, pp. 7934-7938, 1992.

[9] J.-P. Behr, "The proton sponge: a trick to enter cells the viruses did not exploit," Chimia International Journal for Chemistry, vol. 51, no. 1-2, pp. 34-36, 1997.

[10] O. Boussif, F. Lezoualc'h, M. A. Zanta, et al., "A versatile vector for gene and oligonucleotide transfer into cells in culture and in vivo: polyethylenimine," Proceedings of the National Academy of Sciences of the United States of America, vol. 92, no. 16, pp. 7297-7301, 1995.

[11] D. W. Pack, D. Putnam, and R. Langer, "Design of imidazolecontaining endosomolytic biopolymers for gene delivery," Biotechnology and Bioengineering, vol. 67, no. 2, pp. 217-223, 2000.

[12] P. Midoux and M. Monsigny, "Efficient gene transfer by histidylated polylysine/pDNA complexes," Bioconjugate Chemistry, vol. 10, no. 3, pp. 406-411, 1999.

[13] J. G. R. Elferink, "Changes of plasma membrane permeability in neutrophils treated with polycations," Inflammation, vol. 15, no. 2, pp. 103-115, 1991.
[14] M. Gatica, C. C. Allende, M. Antonelli, and J. E. Allende, "Polylysine-containing peptides, including the carboxylterminal segment of the human c-Ki-ras 2 protein, affect the activity of some key membrane enzymes," Proceedings of the National Academy of Sciences of the United States of America, vol. 84, no. 2, pp. 324-328, 1987.

[15] J. H. Kleinschmidt and D. Marsh, "Spin-label electron spin resonance studies on the interactions of lysine peptides with phospholipid membranes," Biophysical Journal, vol. 73, no. 5, pp. 2546-2555, 1997.

[16] T. Kato, S. Lee, S. Ono, et al., "Conformational studies of amphipathic $\alpha$-helical peptides containing an amino acid with a long alkyl chain and their anchoring to lipid bilayer liposomes," Biochimica et Biophysica Acta, vol. 1063, no. 2, pp. 191-196, 1991.

[17] A. Graf, K. S. Jack, A. K. Whittaker, S. M. Hook, and T. Rades, "Protein delivery using nanoparticles based on microemulsions with different structure-types," European Journal of Pharmaceutical Sciences, vol. 33, no. 4-5, pp. 434-444, 2008.

[18] P. Calvo, C. Remuñán-López, J. L. Vila-Jato, and M. J. Alonso, "Development of positively charged colloidal drug carriers: chitosan-coated polyester nanocapsules and submicronemulsions," Colloid and Polymer Science, vol. 275, no. 1, pp. 46-53, 1997.

[19] P. Calvo, J. L. Vila-Jato, and M. J. Alonso, "Evaluation of cationic polymer-coated nanocapsules as ocular drug carriers," International Journal of Pharmaceutics, vol. 153, no. 1, pp. 41-50, 1997.

[20] P. Calvo, C. Remuñán-López, J. L. Vila-Jato, and M. J. Alonso, "Novel hydrophilic chitosan-polyethylene oxide nanoparticles as protein carriers," Journal of Applied Polymer Science, vol. 63, no. 1, pp. 125-132, 1997.

[21] S. Magdassi, U. Bach, and K. Y. Mumcuoglu, "Formation of positively charged microcapsules based on chitosan-lecithin interactions," Journal of Microencapsulation, vol. 14, no. 2, pp. 189-195, 1997.

[22] I. Henriksen, S. R. Vågen, S. A. Sande, G. Smistad, and J. Karlsen, "Interactions between liposomes and chitosan II: effect of selected parameters on aggregation and leakage," International Journal of Pharmaceutics, vol. 146, no. 2, pp. 193 203, 1997.

[23] W. Y. Lee, E. Y. Moon, J. Lee, et al., "Toxicities of ${ }^{166}$ Holmiumchitosan in mice," Arzneimittel-Forschung, vol. 48, no. 3, pp. 300-304, 1998.

[24] T. J. Aspden, J. D. T. Mason, N. S. Jones, J. Lowe, Ø. Skaugrud, and L. Illum, "Chitosan as a nasal delivery systemml: the effect of chitosan solutions on in vitro and in vivo mucociliary transport rates in human turbinates and volunteers," Journal of Pharmaceutical Sciences, vol. 86, no. 4, pp. 509-513, 1997.

[25] R. Bodmeier, H. Chen, and O. Paeratakul, "A novel approach to the oral delivery of micro- or nanoparticles," Pharmaceutical Research, vol. 6, no. 5, pp. 413-417, 1989.

[26] L. Illum, N. F. Farraj, and S. S. Davis, "Chitosan as a novel nasal delivery system for peptide drugs," Pharmaceutical Research, vol. 11, no. 8, pp. 1186-1189, 1994.

[27] S. Miyazaki, A. Nakayama, M. Oda, M. Takada, and D. Attwood, "Chitosan and sodium alginate based bioadhesive tablets for intraoral drug delivery," Biological \& Pharmaceutical Bulletin, vol. 17, no. 5, pp. 745-747, 1994.

[28] H. Tozaki, J. Komoike, C. Tada, et al., "Chitosan capsule for colon-specific drug delivery: improvement of insulin absorption from the rat colon," Journal of Pharmaceutical Sciences, vol. 86, no. 9, pp. 1016-1021, 1997. 
[29] P. Artursson, T. Lindmark, S. S. Davis, and L. Illum, "Effect of chitosan on the permeability of monolayers of intestinal epithelial cells (Caco-2)," Pharmaceutical Research, vol. 11, no. 9, pp. 1358-1361, 1994.

[30] S. Dumitriu, Polymeric Biomaterials, Marcel Dekker, New York, NY, USA, 1994.

[31] E. Allemann, R. Gurny, and E. Doelker, "Drug-loaded nanoparticles: preparation methods and drug targeting issues," European Journal of Pharmaceutics and Biopharmaceutics, vol. 39, no. 5, pp. 173-191, 1993.

[32] P. Couvreur and C. Vauthier, "Polyalkylcyanoacrylate nanoparticles as drug carrier: present state and perspectives," Journal of Controlled Release, vol. 17, no. 2, pp. 187-198, 1991.

[33] S. J. Douglas, L. Illum, S. S. Davis, and J. Krueter, "Particle size and size distribution of poly(butyl-2-cyanoacrylate) nanoparticles-I: influence of physicochemical factors," Journal of Colloid and Interface Science, vol. 101, no. 1, pp. 149-158, 1984.

[34] F. Lescure, C. Zimmer, D. Roy, and P. Couvreur, "Optimization of polyalkylcyanoacrylate nanoparticle preparation: influence of sulfur dioxide and $\mathrm{pH}$ on nanoparticle characteristics," Journal of Colloid and Interface Science, vol. 154, no. 1, pp. 7786, 1992.

[35] S. J. Douglas, L. Illum, and S. S. Davis, "Particle size and size distribution of poly(butyl 2-cyanoacrylate) nanoparticlesII: influence of stabilizers," Journal of Colloid and Interface Science, vol. 103, no. 1, pp. 154-163, 1985.

[36] H. C. Birnboim and J. Doly, "A rapid alkaline extraction procedure for screening recombinant plasmid DNA," Nucleic Acids Research, vol. 7, no. 6, pp. 1513-1523, 1979.

[37] Y. Dong and S.-S. Feng, "Methoxy poly(ethylene glycol)poly(lactide) (MPEG-PLA) nanoparticles for controlled delivery of anticancer drugs," Biomaterials, vol. 25, no. 14, pp. 2843-2849, 2004.

[38] M. Hashida, S. Takemura, M. Nishikawa, and Y. Takakura, "Targeted delivery of plasmid DNA complexed with galactosylated poly(L-lysine)," Journal of Controlled Release, vol. 53, no. 1-3, pp. 301-310, 1998.

[39] H. Maeda and Y. Matsumura, "Tumoritropic and lymphotropic principles of macromolecular drugs," Critical Reviews in Therapeutic Drug Carrier Systems, vol. 6, no. 3, pp. 193-210, 1989.

[40] O. Felt, P. Buri, and R. Gurny, "Chitosan: a unique polysaccharide for drug delivery," Drug Development and Industrial Pharmacy, vol. 24, no. 11, pp. 979-993, 1998.

[41] H. S. Kaş, "Chitosan: properties, preparations and application to microparticulate systems," Journal of Microencapsulation, vol. 14, no. 6, pp. 689-711, 1997.

[42] S.-S. Feng and G. Huang, "Effects of emulsifiers on the controlled release of paclitaxel (Taxol ${ }^{\circledR}$ ) from nanospheres of biodegradable polymers," Journal of Controlled Release, vol. 71, no. 1, pp. 53-69, 2001.

[43] V. Baeyens and R. Gurny, "Chemical and physical parameters of tears relevant for the design of ocular drug delivery formulations," Pharmaceutica Acta Helvetiae, vol. 72, no. 4, pp. 191-202, 1997.

[44] H.-Q. Mao, K. Roy, V. L. Troung-Le, et al., "Chitosan-DNA nanoparticles as gene carriers: synthesis, characterization and transfection efficiency," Journal of Controlled Release, vol. 70, no. 3, pp. 399-421, 2001.

[45] H.-P. Zobel, F. Stieneker, S. Atmaca-Abdel Aziz, et al., "Evaluation of aminoalkylmethacrylate nanoparticles as colloidal drug carrier systems-part II: characterization of antisense oligonucleotides loaded copolymer nanoparticles," European Journal of Pharmaceutics and Biopharmaceutics, vol. 48, no. 1, pp. 1-12, 1999.

[46] J.-P. Behr, "The proton sponge: a trick to enter cells the viruses did not exploit," CHIMIA International Journal for Chemistry, vol. 51, no. 1-2, pp. 34-36, 1997.

[47] R. Hejazi and M. Amiji, "Chitosan-based gastrointestinal delivery systems," Journal of Controlled Release, vol. 89, no. 2, pp. 151-165, 2003.

[48] D. Putnam, C. A. Gentry, D. W. Pack, and R. Langer, "Polymerbased gene delivery with low cytotoxicity by a unique balance of side-chain termini," Proceedings of the National Academy of Sciences of the United States of America, vol. 98, no. 3, pp. 12001205, 2001.

[49] D. Fischer, Y. Li, B. Ahlemeyer, J. Krieglstein, and T. Kissel, "In vitro cytotoxicity testing of polycations: influence of polymer structure on cell viability and hemolysis," Biomaterials, vol. 24, no. 7, pp. 1121-1131, 2003. 

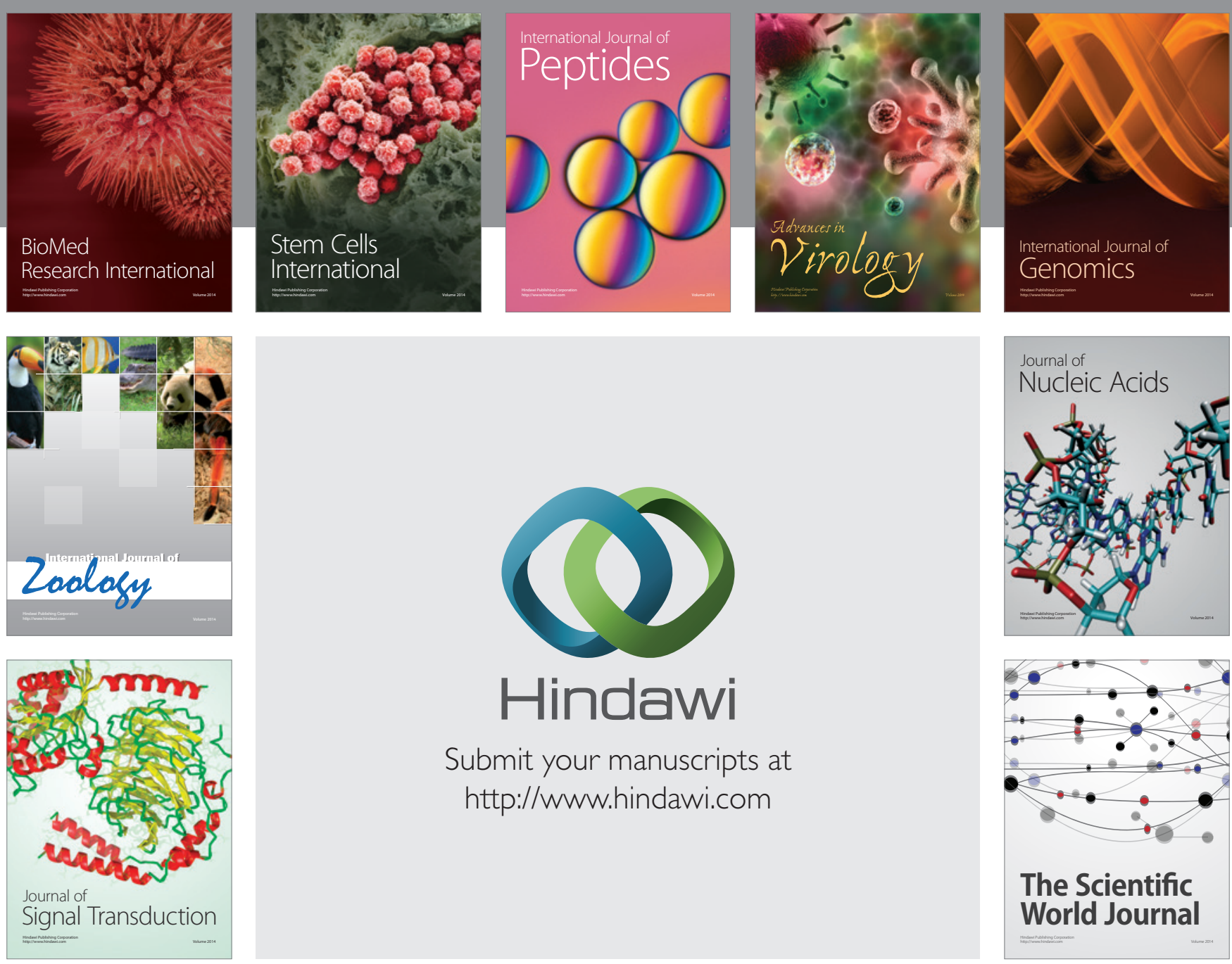

Submit your manuscripts at

http://www.hindawi.com
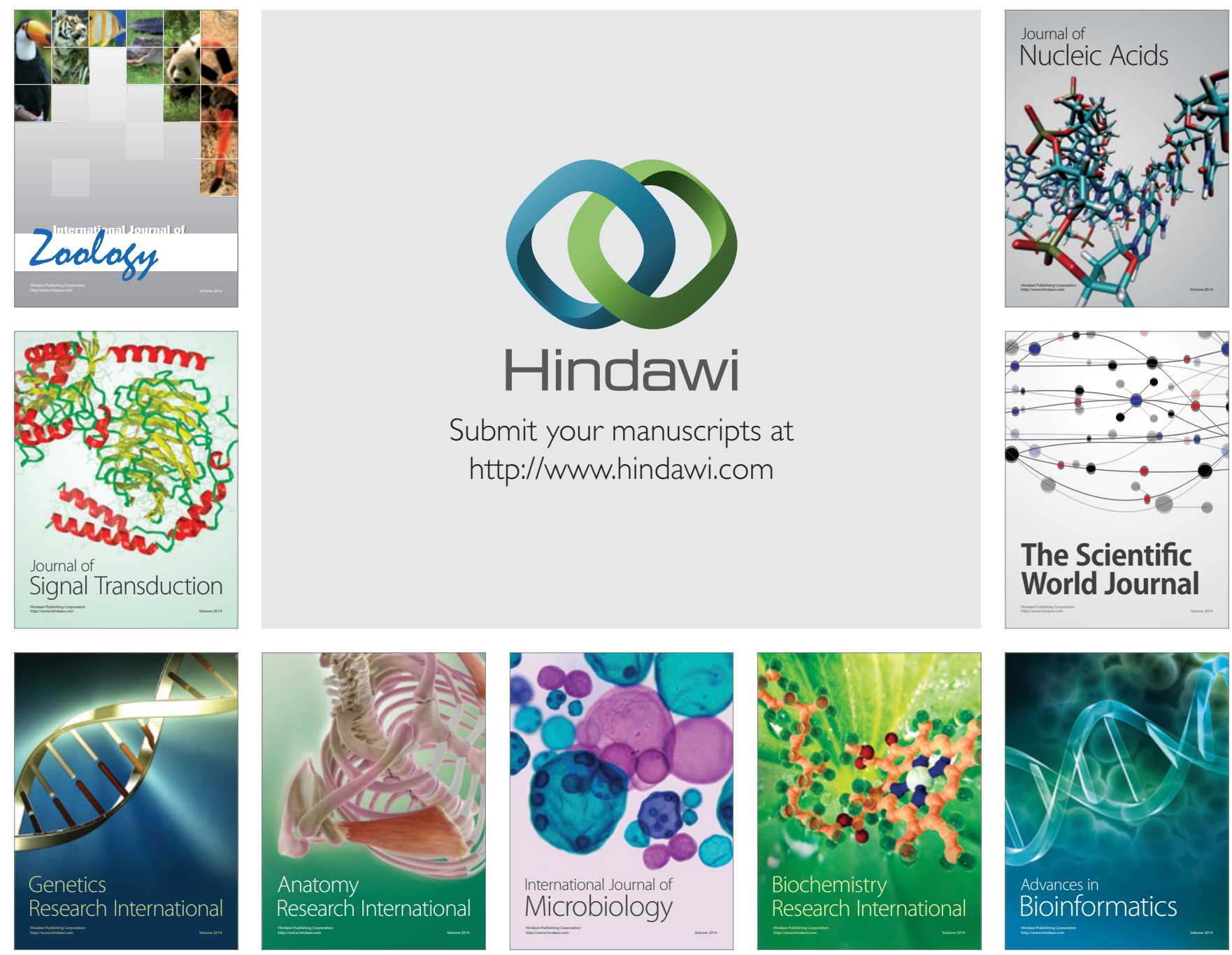

The Scientific World Journal
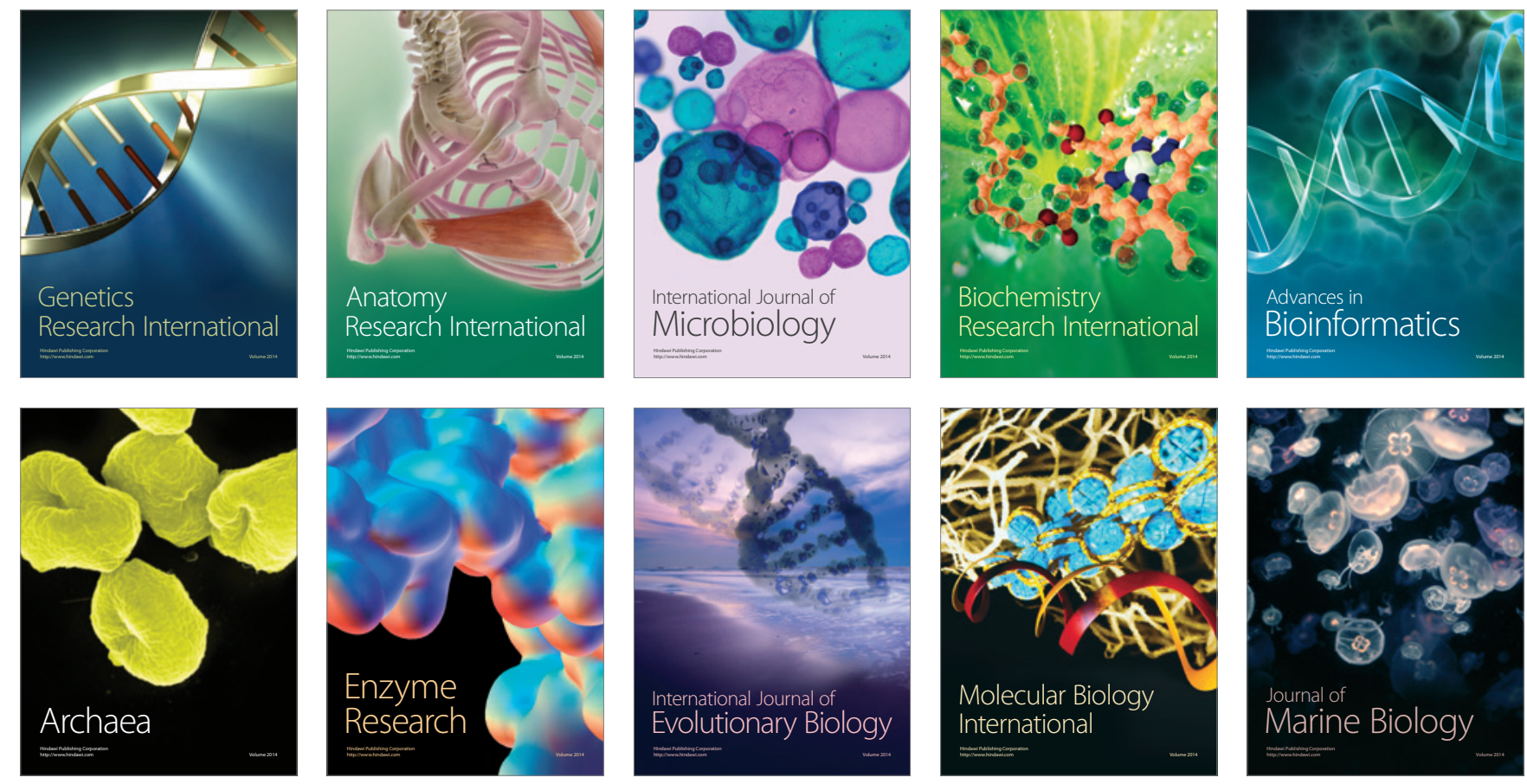